\title{
Role of Ion Channel Modulator in Diabetes Mellitus
}

\author{
Poonam Singh, Vaibhav Walia and Prabhakar Kumar Verma* \\ Department of Pharmaceutical Sciences, Maharshi Dayanand University, Rohtak, \\ Haryana, India \\ *Corresponding Author: Prabhakar Kumar Verma, Department of Pharmaceutical \\ Sciences, Maharshi Dayanand University, Rohtak, Haryana, India.
}

Received: November 01, 2021

Published: December 16, 2021

(C) All rights are reserved by Prabhakar

Kumar Verma., et al.

\begin{abstract}
Ion channel playa essential role in glucose induced insulin secretion. Insulin secretion by $\beta$ cells of pancreas that response to an increase the blood glucose levels in body. It plays an important role to maintain homeostasis of glucose. Glucose stimulated insulin secretion (GSIS) in $\beta$ cells of pancreas have explored. Glucose enters in cell membrane then later in metabolic pathway. In this manner the ratio of ATP/ADP (adenosine triphosphate/adenosine di-phosphate) increase cause to closing of ATP-sensitive potassium channel $\left(\mathrm{K}_{\text {ATP }}\right)$ channels leading to depolarization of membrane. Depolarization cause to opening of voltage gated sodium channels (Nav) later voltage dependent calcium channels (Cav). Increasing of calcium in intra-cellular membrane cause the insulin exocytosis from insulin containing vesicles. Then electrical activity of $\beta$ cell of pancreas plays an important role in the GSIS. Furthermore, incretins, some neurotransmitters hormones and growth factors, can modulate the GSIS. In this review we discuss on ion channels and types of ion channel, role of $\mathrm{K}_{\mathrm{ATP}}$, Nav, Cav and $\mathrm{Cl}$ channels in insulin secretion, expression of ion channel, alteration of ion channel in diabetes mellitus disorder, ion channel as a drug target in diabetes mellitus.
\end{abstract}

Keywords: Ion Channel; Diabetes Mellitus; Insulin Secretion; Pancreatic B Cell

\section{Abbreviations}

GSIS: Glucose Stimulated Insulin Secretion; ATP: Adenosine Triphosphate; ADP: Adenosine Diphosphate; STZ: Streptozotocin; $\mathrm{K}_{\text {ATP: }}$ ATP Sensitive Potassium Channel; VGSC: Voltage-Gated Sodium Channel; VGCC: Voltage-Gated Calcium Channel; PKA and PKC: Protein Kinase A, Protein Kinase C; DRG: Dorsal Root Ganglion; MgADP: Magnisum Salt Adenosine Diphosphate.

\section{Background}

Ion channels are essential, pore forming proteins (amino acid) that help movement of ions from one side of a membrane to the other membrane. They change in electric field and ion concentrations after it play vital roles in physiological processes, one cell to another cell communication, cell proliferation and secretion [1]. They are found in a vital number of organisms from bacteria, vi- ruses, plants and mammals. Ion channels are three hundred types present in living cell [2]. They are classified on the basis of opening and closing ion channel. It is mainly divided two types. First is voltage gated (sensitive) ion channel second is voltage insensitive. Voltage gated ion channel mainly sodium, potassium, calcium channels. But some others are not voltage gated channel they are ligand gated ion channel such as TRP channels, potassium, chloride channels, ryanodine receptors and ionsitol triphosphate receptors. Firstly, determine the structures of potassium $(\mathrm{K})$ channels [3] then Chloride ( $\mathrm{Cl}$ ) channels [4] and the recent sodium (Na) channels [5] has enhance the knowledge of ion channel based on structures of ion channel. The $\mathrm{K}, \mathrm{Na}, \mathrm{Ca}, \mathrm{Cl}$ and TRP channels has various functional and structural affinities. They have the electrical potential of the membranes of excitable cells such as neurones. Generally, the ion channel plays a role in physiology of membrane. Voltage gated and ligand gated ion channel mainly target for drug 
binding but currently $\mathrm{G}$ protein coupled receptors are the largest target for drugs [6]. Ion channels are related with drug discovery process. The drugs target to ion channel influences the organs and central nervous system (CNS), peripheral nervous system (PNS), and cardiovascular system (CVS) [7].

Ion channels play essential physiological and patho-physiological roles in glucose induced insulin secretion. The production of ATP may be control by mitochondrial ion channels. Calcium store in calcium channels affecting the electrical activity by change in secretory granules; it is regulating the maturation of granule and release of insulin during exocytosis [8].

\section{Classification of ion channel}

They are classified on the following basis

- $\quad$ Character of gating.

- Types of ions passing across gates.

- $\quad$ No. of gates.

\section{Character of gating}

They are two types

- $\quad$ Voltage gated ion channel (VGICs)

- $\quad$ Ligand gated ion channel (LGICs)

\section{Voltage gated ion channel (VGICs)}

Voltage gated ion channels mainly critical in neurons. These are trans-membrane ion channel and activated by the change in the channel of electrical potential difference. They have a role in muscle tissues, membrane depolarization and excitable neuronal [9].

They are classified

- Voltage gated calcium channels (Cav)

- Voltage gated sodium channels (Nav)

- Voltage gated potassium channels (Kv)

- $\quad$ Chloride channels $(\mathrm{Cl})$

\section{Ligand gated ion channel (LGICs)}

These are group of trans-membrane channel and opening and closing depend on binding of chemical messenger (1) or neurotransmitter (2). LGICs are present on different site of protein (an allosteric binding site). The LGICs is direct relation between li- gand binding and openings or closing of ion channel. The indirectly function of metabotropic receptor is used as second messenger. Ion channel control by ligand. It is highly specific to one or more ions $\mathrm{Ca}^{2+}, \mathrm{Na}^{+}, \mathrm{K}^{+}, \mathrm{Cl}^{-}$. It is present at synapses and directly convert chemical signal of pre-synaptically released neurotransmitter and quickly into post-synaptic electrical signals [9].

LGICs are classified into three families

- Ionotropic glutamate receptors: Kainate, AMPA, NMDA

- $\quad$ Cys-loop receptors: Glycine, $\mathrm{GABA}_{\mathrm{A}}$, Serotonin

- $\quad$ ATP-gated channels: P2

Types of Ions passing through the gates

- Potassium channels

- Calcium activated potassium channel

- Inward rectifier potassium channels

- Two pore domain potassium channels

- Chloride channels

- Calcium channels

- $\quad$ Sodium channels

- Voltage-gated sodium channels

- Epithelial sodium channels

- Proton channels

- Voltage-gated proton channels

- $\quad$ Non-selective cation channels.

Number of pores

Based on Number of pores in ion channel

- $\quad$ One (1) pore containing channels e.g., all type ion channels.

- Two (2) pores containing channels e.g., TRP channels, catsper channels.

Ion channel's structure

They are divided in four parts

- $\quad$ Opening in the centre for passing of ions

- Ions contain selectively filter to allow passage of specific ions

- $\quad$ One or more gates that open and close

- $\quad$ Sensor for sense, triggering the signal and transmits to gate. 
The Channels are different corresponding to ion. Ion is passing through channel. Ion channel composed number of subunits. Ion Channels belong to largest family. The voltage-gated channels contain 4 subunits with each subunit consist of 6 trans membrane helix. Opening and closing of pore depend on activation of this transmembrane helix [10]. The lining of pore could replace the molecules of water and shielding $\mathrm{K}^{+}$ions, but $\mathrm{Na}^{+}$ions is tiny to allow such as shielding, therefore couldn't pass through. This mechanism was finally confirmed when structure of ion channel was elucidated. Molecular structure of ion channel was proposed by Roderick MacKinnon with help of X-ray crystallography. He won Nobel Prize 2003 in Chemistry. Because of their size small and difficulty of crystallizing integral proteins membrane for X-ray analysis [11].

\section{Calcium channel}

Calcium channels $\left(\mathrm{Ca}^{2+}\right)$ are in the membrane of neurons and excitable cells. Nomenclature of Calcium channels was given by Ertel., et al. [12] and approved by NC-IUPHAR sub-committee on $\mathrm{Ca}^{2+}$ channels [13]. They form heterooligomeric complex. The alpha1 subunit is pore forming and provides the extra-cellular binding site(s) for agonists and antagonists.

\section{Alpha subunit has three types}

- Highly voltage activated di-hydro pyridine sensitive (CaV1.X, L-type) channels.

- Highly voltage activated di-hydro pyridine insensitive (CaV2.x, P/Q-type) channels.

- $\quad$ Low voltage activated (CaV3.x, T-type) channels.

\section{Drugs acting on ion channels}

Calcium channel modulator

Calcium channel blockers (CCB) are inhibiting the calcium channels in cardiac muscle and blood vessels. Decreasing of intra-cellular calcium led to a reduction of muscle contraction or also reduction of cardiac contraction. Decrease the calcium in blood vessels leading to decrease the contraction of the vascular smooth muscle. Vasodilatation is relaxation of muscular walls and increases the diameter of arterial. Decreases of total peripheral resistance (TPR) then relaxation in cardiac contraction and cardiac output decreases. Blood pressure is determined by total peripheral resistance (TPR) and cardiac output [14].
- Calcium channel opener: Polyphenolic flavonoid, Quercetin.

- Calcium channel blocker: Amlodipine, Aranidipine, Azelnidipine, Barnidipine, Benidipine, Cilnidipine, Nifedipine Verapamil, Gallopamil, Fendiline.

Role of voltage-gated calcium (Cav) channel in insulin secretion

Insulin release and glucose sensing, role on voltage dependent calcium channels (VDCCs) or $\mathrm{K}_{\mathrm{ATP}}$ channels, intrinsic relationship with insulin release, due to the close of $\mathrm{K}_{\mathrm{ATP}}$ channels and open of VDCCs through membrane influx of calcium ion. Increase the calcium in intracellular membrane cause the release of insulin [15]. Native pancreatic $\beta$ cells from several species and cell lines have different types of [16], and they are present near insulin granules. The dysfunctions of calcium channels change in insulin secretion, VDCCs play a role in GSIS [17]. The $\operatorname{Cav}\left(\beta_{2}\right)$ and $\operatorname{Cav}\left(\beta_{3}\right)$ subunits could modulate GSIS by interactions between protein kinase $C$ (PKC) isozymes and VGCCs. In pancreatic $\beta$ cells, influx of calcium through interactions of protein-protein, electrical activity and enzymatic responses, playing role in secretion of insulin process. VDCCs also help in survival, development, maturation, death and growth of pancreatic $\beta$ cells [18]. Other reasons of biphasic secretion of insulin process sequential release granules [19], $\mathrm{Ca}^{+2}$ influx through calcium channel increases the $\mathrm{Ca}^{+2}$ and they help in secretion of insulin. They are main contributing to cell Cav current and exocytosis insulin granule in human, mouse and rats of $\beta$ cells of pancreas [20]. Glucose dependent $\mathrm{Ca}^{+2}$ entries by L-type calcium channels and caused the downstream of the membrane depolarisation by decreased $\mathrm{K}_{\text {ATP }}$ channel activity. Calcium channel are defect then loss of function to coupling of calcium dependent insulin secretion from membrane depolarising.

\section{Expression of voltage gated calcium channel in pancreas}

Many Pharmacological activities have showed the 60 to $80 \%$ of release of insulin ratio may be influx of calcium, mainly through L- type $\mathrm{Ca}^{+2}$ channels pathway [21]. The Cav sub family has been expressed in $\beta$ cells. The Cav1.2 lack in transgenic mice $\beta$-cells has been impaired first phase secretion of insulin and glucose intolerance [22]. L- types subunit Cav1.2 and Cav1.3 channels are expression in mouse, rat and human pancreatic $\beta$ cells. $\mathrm{Ca}_{\mathrm{v}} 1.3$ channel is mostly present in human and rat pancreatic $\beta$ cells [23]. They are playing a important role in insulin secretion and cAMP homeosta- 
sis by adenylate cyclise. And Cav1.2 channel is present in pancreatic $\beta$ cells of mouse [24].

The subunit of P/Q type Cav2.1 and R type Cav2.3 are present in humans and mice of pancreatic $\beta$ cells. T type subunit Cav3.1 and Cav3.2 channels in pancreatic $\beta$ cells of rat. [25] these are play a important role in insulin secretion regulation. $G$ protein-coupled receptors, $\mathrm{Ca}^{2+} /$ calmodulin signaling, phosphorylated inositol and protein phosphorylation, regulation of $\mathrm{Ca}^{2+}$ channels activity $\beta$ cells of pancreas in the cell membrane. The subunit of calcium channel complex with the insulin secretion have shown non-insulin dependent diabetic model (NIDDM) animal model the expression of subunit of calcium channel in Zucker diabetic fatty rats. They found the pancreatic islets has decrease levels of expression of $\mathrm{Ca}^{2+}$ channel (L-type) subunit mRNA, decrease the intracellular $\mathrm{Ca}^{2+}$ signalling in high glucose.

\section{Alteration in cav channels in $\beta$ cell pathophysiology}

In the diabetes mellitus disease increases the blood glucose level. Disorder of Cav channels present in $\beta$ cell of pancreas in diabetic animal model and patients of diabetes [26]. In streptozocin (STZ) induced diabetic model and isolated the $\beta$ cell. We observed the pancreatic $\beta$ cells rats showed drastic upregulation of both subunit Cav1 and Cav3 channel. The effect is most likely on the Cav1 channel due to increase in the activity rather than in the number of Cav channels, because the binding sites are dihydropyridine (DHP) in diabetic $\beta$ cell decrease [27]. STZ pancreatic islets shown expression of Cav channel subunit genes significantly decrease. The directly depolarization with $20 \mathrm{~mm}$ arginine induces a more pronounced calcium ion increase in diabetic $\beta$ cell comparison with control $\beta$ cell. Therefore, the pancreatic islets of rats exhibit blunted calcium ion increase and secretion of insulin after stimulation of glucose due to sensitivity of glucose impaired of $\beta$ cell $\mathrm{K}_{\mathrm{ATP}}$ channels. Therefore, in vivo activity Cav channels hyper activation in STZ pancreatic $\beta$ cell can rarely occur. The suburbanite Cav1 and Cav 3 channel activity in the STZ $\beta$ cell are already significantly enhanced when the cells are depolarized to potentials within the physiological range $(20 \mathrm{mV})$ [18]. Similar changes in $\beta$ cell Cav channel activity have been visualized in the Goto-Kakizaki rats a NIDDM [28].

\section{Sodium channel}

The main role of sodium channel

- Initiation
- $\quad$ Propagation of action potentials in excitable cells and neurons for e.g., endocrine cells and myocytes.

The cell membrane depolarizing by millivolts $(\mathrm{mV})$ then sodium channels is insensitive and sensitive in milliseconds (ms). Sodium ions $\left(\mathrm{Na}^{+}\right)$influx through integral membrane proteins, cell membrane is depolarizing, initiating the action potential. The voltage gated sodium channel (VGSC) is multi-meric complex and wide.

\section{Sodium channel modulator}

The Sodium channel blockers drugs with sodium channels cause imbalance of sodium ions conduction. Voltage gated sodium channel play important role in action potentials. Opening of sodium channel, change in cells membrane action potential then $\mathrm{Na}^{+}$ has been move into cell, down their electro-chemical gradient then depolarizing the cell membrane. Numerous sodium channels localized in region of cells membrane later action potential has propagated. The ability of sodium channels to assume a closed in-activated state causes the refractory period and critical for propagation of action potentials down an axon channel. The sodium channels have nine sub-members channels. These channels are named Nav1.1 through Nav1.9 [29].

The naturally substances activate (opener) sodium channels are classified

- Alkaloid based toxins: Ciguatoxin, Batrachotoxin, Delphinine, Brevetoxin, Veratridine, Grayanotoxin, Aconitine.

- Gating modifiers: Scorpion venom toxins, Birtoxin, $\mu$-conotoxin, $\delta$-atracotoxin.

\section{Sodium channel blocker}

Ranolazine, Phenytoin, Disopyramide, Lidocaine, Mexiletine, Triamterene, Lamotrigine, Amiloride, Moricizine, Oxcarbazepine.

Role of sodium channels in insulin secretion

The negative potentials on $\beta$ cell of pancreas the voltage gated sodium channels exhibit inactive. Voltage dependent sodium channels (VDSC) play an important role in excitable cell [1], In 1988 VDSC are present in pancreatic islets of mouse was described by Plant. VDSC are effect by membrane potential, it is activated in response to cause depolarization of cell membrane and inactivated as a consequence of sustained depolarization. The $\beta$ cell of pancreas have a voltage dependent $\mathrm{Na}^{+}$current that, being to voltage dependence of inactivation, is unlikely to play a role in glucose 
stimulated electrical activity. At the resting potential mostly VDSC are closed or inactivated, and their inactivation can be removed by hyper polarization of cell membrane [18].

\section{Expression of sodium channel in pancreas}

VGSC modulators can be modifying the ratio of insulin secretion. The sub-types of VGSC Nav1.6 and Nav1.7 subtypes expressed in human $\beta$ cell of pancreas and subtypes Nav1.3 and Nav1.7 expressed in mice and rats. Sub types Nav1.7 are highly expressed and sub types $\mathrm{Na}_{\mathrm{v}} 1.3$ significantly contribute current by sodium channel among $\beta$ cell of pancreas [30]. Ernest and co-workers were reported that sub type Nav1.7 expressed in $\beta$ cells of pancreas that causes defects in release of insulin. Velasco and co-workers in 2016 were reported that Nav channels cause activation of $\beta$ cell of pancreas and secretion of insulin then closure of glucose dependent $\mathrm{K}_{\mathrm{ATP}}$ channel led to increases depolarization, which activate the influx of $\mathrm{Ca}^{+2}$ and secretion of insulin. Influx $\mathrm{Na}^{+}$depolarization of membrane. Fast activation of $\mathrm{Na}^{+}(-10 \mathrm{mV})$, after it begins inactivation of this current in milliseconds, opening of $\mathrm{Ca}^{+2}$ channel [31]. Different types of ion channel is express in $\beta$ cell of pancreas and leads to generation of electrical signal. It coupled with blood glucose concentration then determines the ratio of insulin release e.g., $\mathrm{K}^{+}$and $\mathrm{Ca}^{+2}$ channels.

\section{Alteration in sodium channel in pancreas}

The alterations of sodium channels in nociceptive C-fiber dorsal root ganglion (DRG) neurons have been involved in diabetic neuropathy (DN). The Immunofluorescence study have been showed significant increases in the levels and number of large DRG neurons from diabetic rats expressing $\mathrm{Na}_{\mathrm{v}} 1.2, \mathrm{Na}_{\mathrm{v}} 1.3, \mathrm{Na}_{\mathrm{v}} 1.7$, and $\mathrm{Na}_{\mathrm{v}} 1.9$ whereas $\mathrm{Na}_{\mathrm{v}} 1.8$ decreased and decrease in the number of nodes of ranvier expressing $\mathrm{Na}_{\mathrm{v}} 1.8$ and in staining intensity of $\mathrm{Na}_{\mathrm{v}} 1.6$ and $\mathrm{Na}_{\mathrm{v}} 1.8$ at nodes. The alterations of sodium channels occur in large DRG neurons and A-fibers and play role in diabetic sensory neuropathy (DNS) [32].

\section{Potassium channels}

Potassium $\left(\mathrm{K}^{+}\right)$channels are largest family of ion channel. It is also provided advances computational biology a pattern for study of membrane proteins included for transport of ion channels. Computational biology is useful to recollect the $\mathrm{K}^{+}$channel of molecular properties and understood the of X-ray structure. K channels are tetrameric. Various family of $\mathrm{K}^{+}$channels present in the animals, $\mathrm{K}^{+}$ channel structure is derived from bacterial channel (Streptomyces lividans). Kv channels have very complicated TM topology. Based on opening and closing gating $\mathrm{Kv}$ and potassium channel of streptomyces A (KcsA) channels are differentiate. Lowering of pH KcsA is openand cell membrane depolarisations activate the Kv channels.।

\section{Potassium channel modulator}

They are prolonging the repolarisation and action potential [33]. The prolongation of refractory period and action potential duration, the maintaing of normal conduction velocity. E.g.: Azimilide, Bretylium, Clofilium, Tedisamil, Sematilide.

\section{Potassium channel blocker}

Sulfonylureas, Aminopyridine, Amiodorane, Sotalol, Dofetilide.

\section{Potassium channel opener}

Adenosine, Diazoxide, Minoxidil, Nicorandil, Cromakalim, Levocromakalim, Bimakalim,Aprikalim, Pinacidil, Retigabine, Flupirtine.

Role of potassium channels in insulin secretion

Potassium channels are three (3) types they are involved in secretion of insulin in $\beta$ cells pancreas. Firstly ATP-sensitive potassium channel $\left(\mathrm{K}_{\text {ATP }}\right)$ channels, it is mainly regulation of glucose homeostasis and consist of four subunits of sulfonylurea receptor and four pore forming Kir6 subunits. $\mathrm{K}_{\text {ATP }}$ channel modulator play role secretion of insulin. Currently sulphonyl urea (SU) drugs used in treatment diabetes mellitus [33]. Sulphonyl urea drugs blocking of $\mathrm{K}_{\text {ATP }}$ then cause depolarizes the membrane action potential of $\beta$ cells and cause secretion of insulin. Second, calcium activated potassium channel (KCa) channels it is in pancreatic. Activation of KCa channel increase calcium conc. in intracellular membrane. KCa channels maintain the inter-connection between intracellular $\mathrm{Ca}^{2+}$ influx and cell membrane potential also determine insulin exocytosis. Charybdotoxin at Low conc. inhibit the KCa channels and don't have effect on insulin release from pancreatic islets either on the membrane potential of $\beta$ cells. TheKCa channels suggest that regulate electrical activity and release of insulin in $\beta$ cells of pancreas, the main role play KCa channels secretion of insulin remains controversy. Third type of Kv channels is divided into four gene family, Kv1 to Kv4 (Shaker, Shab, Shaw, Shal-type subunits) and activation of glucose stimulated insulin secretion in isolated rat islets. 
Expression of potassium channel in pancreas

Voltage gated potassium channel Kv channel have different subunits Kv1.4, Kv1.6, Kv2.1, and Kv3.2, are present in $\beta$ cells of pancreas. Kv1.5 is mainly present in human insulinoma. Sub type Kv2.1, Kv3.2, Kv6.2, and Kv9.3 are expressed in $\beta$ cells, Kv3.1 and Kv6.1 are expressed in $\alpha$-cell and that Kv2.2 is expressed in $\delta$-cells. Kv2.1, Shab-type is highly expressed in $\beta$ cells. Kv2.1 may represent a novel target for the treatment of type 2 diabetes [34].

\section{Alteration in potassium channel in diabetes}

Structural and functional defects in $\mathrm{K}_{\mathrm{ATP}}$ channels cause impairment of insulin release or secretion later cause of diseases. It was firstly described in 1981the glucose level increase to promote the secretion of insulin in a concentration dependent manner in isolated tissue. Alterations in the metabolic signal then alteration in $\mathrm{K}_{\text {ATP }}$ channel sensitivity and electrical signal in $\beta$ cell also disrupt alteration in insulin release in pancreas. The $\mathrm{K}_{\text {ATP }}$ channel activity decrease and absent in the pancreatic $\beta$ cell and it cause in humans congenital hyper-insulinism (CHI). CHI is a rarely and recessive disorder. It is characterized by constitutive insulin secretion and low blood glucose. But sometimes it is untreated case of mentally retardation and death. In the $\mathrm{K}_{\mathrm{ATP}}$ channel mutations the channel expression is reduce and decrease activation of channel bymagnesium salt (MgADP), or dismiss the channel activity, excitability of membrane decreases and impair sensing of glucose by $\beta$ cell of pancreas [35]. In both case animal and human study that mutations of $\mathrm{K}_{\mathrm{ATP}}$ channel cause diabetes.

\section{Chloride channel}

Chloride (Cl) channels are regulating the excessive sensitivity of skeletal, neurones cardiac, apoptosis, smooth muscle, cell volume regulation, acidification of internal or extracellular compartments and trans-epithelial transport and cell cycle [36].

\section{Chloride channel modulator}

Chloride channels are activated $\mathrm{Ca} 2+$, extracellular ligands, voltage, and $\mathrm{pH}$ activate others. Eg: Selamectin.

Selamectin is replace the glutamate and interaction with receptors then opening of chloride channels at neuron and musclepresent in parasites [37].

Role of Chloride Channels in insulin secretion

Chloride (Cl) selective channel are located in $\beta$ cell of pancreas but the physical role are not understood. Chloride conductance increases because depolarising the cells and role in secretion of insulin with help of in-dependent pathways of $\mathrm{K}_{\mathrm{ATP}}$ channel. Chloride channel sub-units are in the secretary granules membranes and chloride flux is coupled with the internal acidification of the granules [38].

\section{Mechanism of ion channels modulator}

Mechanism of calcium channels- $\beta$ cells of panaceas are found to be equipped with $\mathrm{Ca}^{2+}$-channels. It has been reported that the glucose induced insulin secretion follows a biphasic time course consisting of a rapid but transient 1st phase followed by a slower and sustained 2nd phase. In this process (insulin secretion), influx of $\mathrm{Ca}^{2+}$ via L-type $\mathrm{Ca}^{2+}$ channel is responsible for exocytosis of insulin and therefore the pharmacological blockade of L-type $\mathrm{Ca}^{2+}$ channels lead to transient inhibition of glucose-induced electrical activity in the pancreatic $\beta$ cell responsible for reduction in insulin secretion (1st phase insulin secretion was unaffected, but the 2 nd phase secretion was strongly reduced). Further the $\mathrm{Ca}^{2+}$ currents have been shown to be modulated by protein phosphorylation followed by the activation of PKA and PKC leads but the effects of these physiological agonists (like GLP-1 and acetylcholine) acting via these pathway are in general much weaker [39].

\section{Mechanism of potassium channel}

Potassium channel $\left(\mathrm{K}_{\text {ATP }}\right)$ is regulating of glucose induced insulin secretion. Increase the ATP/ADP ratio in the $\beta$-cells of pancreas. It is generated by metabolism and glucose uptake. $\mathrm{K}_{\text {ATP }}$ channels Close to cause depolarization of membrane, influx of calcium, insulin secretion and homeostasis of glucose. In the $\mathrm{K}_{\text {ATP }}$ channels are consist of Kir6.2 pore with SUR1 subunit and regulate insulin release in the $\beta$-cell of pancreas. Influx of calcium through of calcium channel cause of release of Insulin. Hyperglycaemia cause increases the glucose level in the blood and elevated ATP intracellular, depolarization of membrane. $\mathrm{K}_{\text {ATP }}$ channel similar mechanism like sulphonylurea drugs (Example glibenclamide) it is inhibition of $\mathrm{K}_{\mathrm{ATP}}$ channel in the $\beta$-cells of panaceas then depolarization membrane cell. The voltage dependent calcium channels are open increasing of calcium in intracellular cell and $\beta$-cell is stimulating release of insulin. In $\mathrm{K}_{\text {ATP }}$ channels mutation cause physiological dysfunction of this channel leading to pathological consequences such as congenital hyperinsulinism, permanent neonatal diabetes, developmental delay with epilepsy [40]. 
Mechanism of voltage-gated sodium channels - VGSC mediate the influx of sodium ions into the cytosol of cells in response to local membrane depolarization, which results in the generation of the rising phase of an action potential. It has been reported that expression of voltage gated sodium channels increases in the streptozotocin (STZ)-induced diabetic rats with persistent mechanical allodynia suggesting that the expression of the voltage sensitive sodium channels is linked with the pathological conditions involving peripheral nerve injuries, inflammation etc [41-44]. The peripheral nociceptive neurons in DRG express a variety of sodium channel each that plays a key role in the physiology of nociception $[45,46]$. The upregulated expression of sodium channels in diabetic DRG neurons would be expected to increase overall sodium channel density, decrease firing threshold, and causes the hyperexcitability of damaged or injured neurons $[47,48]$. Carbamazepine, a sodium channel inhibitor, has been shown to exert the protective effects on pancreatic $\beta$-cells [49].

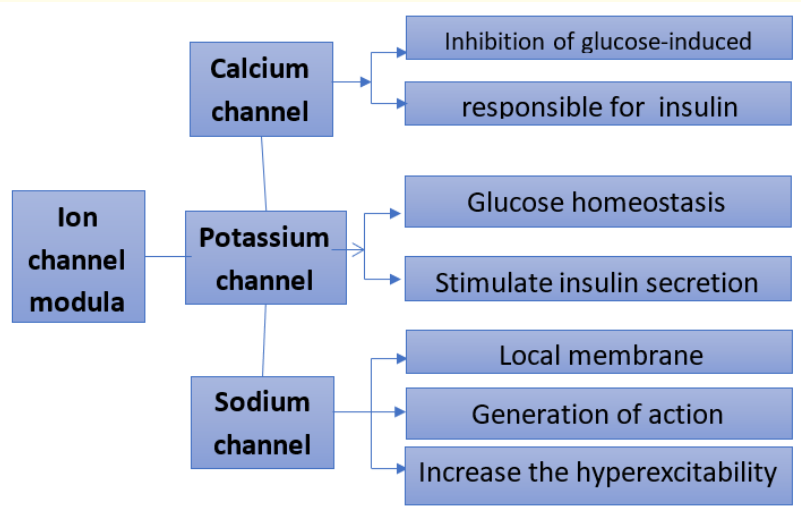

Figure 1: Mechanism of ion channel modulator.

\section{Conclusion and Future Directions}

In this review, we have discussed about ion channel, types of ion channel, role of ion channel in diabetes, expression of ion channel in pancreas and alteration of ion channel in diabetes mellitus. Ion channels modulation plays a key role in secretion of insulin, pathogenesis of diabetes and related symptoms. Inhibition of $\mathrm{K}_{\text {ATP }}$ current by cellular ATP, generating coupling-metabolism to electrical potential, glucose metabolism. In type- 2 diabetes 2 pathways occur. Firstly, reduction in metabolic rate which is not produce ATP sufficient to close $\mathrm{K}_{\text {ATP }}$ channels second is inherited mutations in
ATP sensitive potassium channel (Kir6.2) gene subunit decreased capacity of ATP to close this channel. Depolarisation of cell membrane, $\mathrm{Na}^{+}, \mathrm{Ca}^{+}$, and $\mathrm{K}^{+}$cation channel to regulate oscillations in membrane potential, rate of calcium influx, fusion of granule. Sometimes poorly regulation of channels because defects in acquired and inherited. The adverse effects by drugs could be effect of suppressing or enhancing glucose induced secretion, downstream of $\mathrm{K}_{\text {ATP }}$ channel closure. These channels could be drug targets in treatment of dysfunction of $\beta$ cells. Diabetes mellitus type- 2 is a polygenic disease, only by understanding physiology of $\beta$ cells of pancreas in diabetes. We can hope to have effective treatments in the future.

\section{Ethics Approval and Consent to Participate}

This study approved by the Institutional animal ethics committee (IAEC) Maharshi Dayanand University, Rohtak, Haryana (Regn. No. 1767/RE/S/14/CPCSEA).

\section{Consent for Publication}

Not applicable.

\section{Availability of Data Materials}

The data sets generated during the current study are available from the corresponding author on reasonable request.

\section{Competing Interests}

The authors declare that they have no competing interests.

\section{Funding}

Not available of any type of funding source.

\section{Author's Contribution}

PS and VW conducted the experimental studies and data analyses. PKV conceptualized, designed and directed the study. PS, VW and PKV finalized the manuscript. All authors read and approved the final version of the manuscript.

\section{Acknowledgments}

Thanks to Head, Department of Pharmaceutical Sciences, M. D. University, Rohtak for kind support for providing internet facilities etc. 


\section{Bibliography}

1. Hille B. "Ion channels of excitable membranes. Sinauer Associates". Sunderland, MA (2001): 814.

2. Gabashvili A., et al. "Templating mesoporous silica with chiral block copolymers and its application for enantioselective separation". The Journal of Physical Chemistry B 111.38 (2007): 11105-10.

3. Doyle DA., et al. "The structure of the potassium channel: molecular basis of $\mathrm{K}+$ conduction and selectivity". Science 280.5360 (1998): 69-77.

4. Dutzler R., et al. "X-ray structure of a ClC chloride channel at $3.0 \AA$ A reveals the molecular basis of anion selectivity". Nature 415.6869 (2002): 287-294.

5. Payandeh J., et al. "The crystal structure of a voltage-gated sodium channel". Nature 475.7356 (2011): 353-358.

6. Overington JP., et al. "How many drug targets are there?". Nature reviews Drug discovery 5.12 (2006): 993-996.

7. Anger T., et al. "Medicinal chemistry of neuronal voltage-gated sodium channel blockers". Journal of medicinal chemistry 44.2 (2001): 115-137.

8. Proks P and Lippiat JD. "Membrane ion channels and diabetes". Current pharmaceutical design 12.4 (2006): 485-501

9. Parrott A., et al. "Role of rural land use management in flood and coastal risk management". Journal of Flood Risk Management 2.4 (2009): 272-284.

10. Armstrong CM and Bezanilla F. "Charge movement associated with the opening and closing of the activation gates of the $\mathrm{Na}$ channels". The Journal of general physiology 63.5 (1974): 533552.

11. Long SB., et al. "Crystal structure of a mammalian voltage-dependent Shaker family K+ channel”. Science 309.5736 (2005): 897-903.

12. Ertel EA., et al. "Nomenclature of voltage-gated calcium channels". Neuron 25.3 (2000): 533-535.

13. Catterall WA., et al. "International Union of Pharmacology. XLVII. Nomenclature and structure-function relationships of voltage-gated sodium channels". Pharmacological reviews 57.4 (2005): 397-409.

14. Nelson M. "Drug treatment of elevated blood pressure". Australian Prescriber 33.4 (2010): 108-112.
15. Ashcroft FM and Rorsman P. "Electrophysiology of the pancreatic $\beta$-cell". Progress in biophysics and molecular biology 54.2 (1989): 87-143.

16. Hiriart M and Aguilar-Bryan L. "Channel regulation of glucose sensing in the pancreatic $\beta$-cell”. American Journal of Physiology-Endocrinology and Metabolism 295.6 (2008): E12981306.

17. Kitaguchi T., et al. "Extracellular calcium influx activates adenylate cyclase 1 and potentiates insulin secretion in MIN6 cells". Biochemical Journal 450.2 (2013): 365-373.

18. Davalli AM., et al. "Dihydropyridine-sensitive and-insensitive voltage-operated calcium channels participate in the control of glucose-induced insulin release from human pancreatic $\beta$ cells". Journal of Endocrinology 150.2 (1996): 195-203.

19. Schmutz J., et al. "Genome sequence of the palaeopolyploid soybean". nature 463.7278 (2010): 178-183.

20. Iwashima Y., et al. "Expression of calcium channel mRNAs in rat pancreatic islets and downregulation after glucose infusion". Diabetes 42.7 (1993): 948-955.

21. Scholze A., et al. "Functional expression and characterization of a voltage-gated CaV1. 3 ( $\alpha 1 \mathrm{D}$ ) calcium channel subunit from an insulin-secreting cell line". Molecular Endocrinology 15.7 (2001): 1211-1221.

22. Rorsman P., et al. "Regulation of calcium in pancreatic $\alpha$-and $\beta$-cells in health and disease". Cell calcium 51.3-4 (2012): 300308.

23. Hiriart M and Matteson DR. "Na channels and two types of Ca channels in rat pancreatic $B$ cells identified with the reverse hemolytic plaque assay". The Journal of general physiology 91.5 (1988): 617-639.

24. Roe MW., et al. "NIDDM is associated with loss of pancreatic beta-cell L-type Ca2+ channel activity". American Journal of Physiology-Endocrinology and Metabolism 270.1 (1996): E133-140.

25. Kato S., et al. "Increased calcium-channel currents of pancreatic $\beta$ cells in neonatally streptozocin-induced diabetic rats". Metabolism 43.11 (1994): 1395-1400.

26. Thomas Jessell., et al. Principles of neural science (2000).

27. Braun M., et al. "Voltage-gated ion channels in human pancreatic $\beta$-cells: electrophysiological characterization and role in insulin secretion". Diabetes 57.6 (2008): 1618-1628. 
28. Vignali S., et al. "Characterization of voltage-dependent sodium and calcium channels in mouse pancreatic A-and B-cells". The Journal of physiology 572.3 (2006): 691-706.

29. Suckale J and Solimena M. "The insulin secretory granule as a signaling hub". Trends in Endocrinology \& Metabolism 21.10 (2010): 599-609.

30. Satin LS., et al. "Inactivation of HIT cell Ca2+ current by a simulated burst of Ca2+ action potentials". Biophysical journal 66.1 (1994): 141-148.

31. Hong S and Wiley JW. "Altered expression and function of sodium channels in large DRG neurons and myelinated A-fibers in early diabetic neuropathy in the rat". Biochemical and biophysical research communications 339.2 (2006): 652-660.

32. Trujillo TC and Nolan PE. "Antiarrhythmic agents". Drug safety 23.6 (2000): 509-32.

33. Drews G., et al. "Electrophysiology of islet cells". Advances in Experimental Medicine and Biology (2010): 115-163.

34. Renström E., et al. "Sulfonylurea-mediated stimulation of insulin exocytosis via an ATP-sensitive $\mathrm{K}+$ channel-independent action". Diabetes 51.1 (2002): S33-S36.

35. Tabcharani JA and Misler S. "Ca2+-activated $\mathrm{K}+$ channel in rat pancreatic islet B cells: permeation, gating and blockade by cations". Biochimica et Biophysica Acta (BBA)-Biomembranes 982.1(1989): 62-72.

36. Henquin JC. "Role of voltage-and Ca 2+-dependent $\mathrm{K}+$ channels in the control of glucose-induced electrical activity in pancreatic B-cells". PflügersArchiv 416.5 (1990): 568-572.

37. Philipson LH., et al. "Sequence and functional expression in Xenopus oocytes of a human insulinoma and islet potassium channel". Proceedings of the National Academy of Sciences 88.1 (1991): 53-7.

38. Koster JC., et al. "Targeted overactivity of $\beta$ cell KATP channels induces profound neonatal diabetes". Cell 100.6 (2000): 645654.

39. Sakura H., et al. "Glucose modulation of ATP-sensitive K-currents in wild-type, homozygous and heterozygous glucokinase knock-out mice". Diabetologia 41.6 (1998): 654-659.

40. Ashcroft SJ and Ashcroft FM. "Properties and functions of ATPsensitive K-channels”. Cellular signalling 2.3 (1990): 197-214.
41. Rorsman P., et al. "Regulation of calcium in pancreatic $\alpha$-and $\beta$-cells in health and disease". Cell calcium 51.3-4 (2012): 300308.

42. Namkung W., et al. "Inhibition of Ca2+-activated Cl- channels by gallotannins as a possible molecular basis for health benefits of red wine and green tea". The FASEB Journal 24.11 (2010): 4178-4186.

43. Iden S., et al. "A distinct PAR complex associates physically with VE-cadherin in vertebrate endothelial cells". EMBO reports 7.12 (2006): 1239-1246.

44. Campbell JD., et al. "Potassium channel regulation". EMBO reports 4.11 (2003): 1038-1042.

45. Jing X., et al. "Ca V 2.3 calcium channels control second-phase insulin release". The Journsal of clinical investigation 115.1 (2005): 146-154.

46. Ämmälä C., et al. "Calcium-independent potentiation of insulin release by cyclic AMP in single $\beta$-cells". Nature 363.6427 (1993): 356-358.

47. Ammälä C., et al. "Activation of protein kinases and inhibition of protein phosphatases play a central role in the regulation of exocytosis in mouse pancreatic beta cells". Proceedings of the National Academy of Sciences 91.10 (1994): 4343-4347.

48. Renström E., et al. "Neurotransmitter-induced inhibition of exocytosis in insulin-secreting $\beta$ cells by activation of calcineurin". Neuron 17.3 (1996): 513-522.

49. Black JA., et al. "Changes in the expression of tetrodotoxin-sensitive sodium channels within dorsal root ganglia neurons in inflammatory pain". Pain 108.3 (2004): 237-247.

\section{Assets from publication with us}

- Prompt Acknowledgement after receiving the article

- Thorough Double blinded peer review

- Rapid Publication

- Issue of Publication Certificate

- High visibility of your Published work

Website: www.actascientific.com/

Submit Article: www.actascientific.com/submission.php

Email us: editor@actascientific.com

Contact us: +919182824667 